
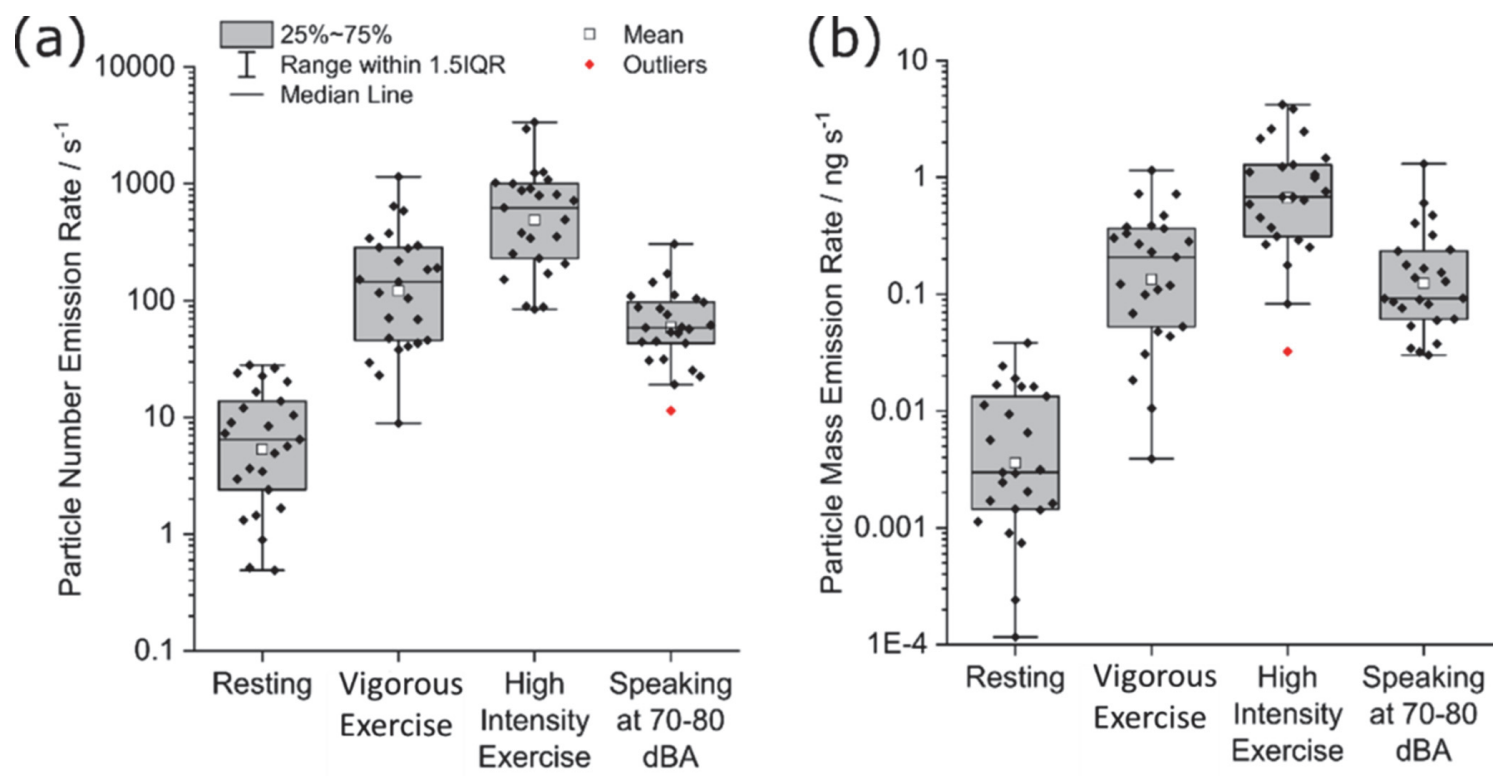

Abstract T5 Figure 1 Box and whisker plots showing (a) Aerosol number emission rates (aerosol number concentration normalised for ventilation) (b) Aerosol mass emission rates (aerosol mass normalised for ventilation) across the same series of activities, for all 25 participants

high intensity exercise $\left(0 \cdot 42 \mu \mathrm{g} / \mathrm{m}^{-3}, \mathrm{p}=0 \cdot 083\right)$. Rest and exercise demonstrated similar aerosol size distributions, however speaking emitted an additional, larger mode at $2-3 \mu \mathrm{m}$. Mean minute ventilation was $11 \mathrm{~L} / \mathrm{min}, 15 \mathrm{~L} / \mathrm{min}, 63 \mathrm{~L} / \mathrm{min}$ and $114 \mathrm{~L} /$ min at rest, speaking, vigorous exercise and high intensity exercise, respectively. Median mass emission rate (aerosol mass concentration normalised for ventilation) produced by speaking, $0.092 \mathrm{ng} / \mathrm{s}^{-1}$, was not different to vigorous exercise, $0 \cdot 207 \mathrm{ng} / \mathrm{s}^{-1},(\mathrm{p}=0 \cdot 726)$ but was lower than high intensity exercise $\left.0.682 \mathrm{ng} / \mathrm{s}^{-1}, \mathrm{p}<0.001\right)$.

Interpretation The size distribution of airborne particles emitted during exercise, match that of breathing at rest, with increased minute ventilation a primary driver of the increased aerosol mass emissions that occur during exertion. Aerosol mass emission rates during vigorous exercise are not different to speaking at a conversational, to loud conversational volume. These findings enhance our understanding of particle release during the fundamental physiological process of exercise, enabling appropriate mitigations for airborne pathogens, including SARS-CoV-2.

Funding The PERFORM 2 study was funding by EPSRC.

\section{T6 THERAPEUTICALLY TARGETING PTBP1/PKM2-DRIVEN GLYCOLYSIS IN ENDOTHELIAL CELLS: A NOVEL APPROACH TO TREAT PULMONARY ARTERIAL HYPERTENSION}

I Cuthbertson, R Sutcliffe, NW Morrell, P Caruso. University of Cambridge, Cambridge, UK

\subsection{6/thorax-2021-BTSabstracts.6}

Background Pulmonary Arterial Hypertension (PAH) is an often-fatal disease, characterised by the development of apoptosis-resistant, hyperproliferative, and hyper-glycolytic endothelial cells (ECs). Loss-of-function BMPR2 mutations and metabolic dysfunction are pivotal to PAH EC dysfunction. Enhanced expression of glycolysis enzyme pyruvate kinase M2 isoform (PKM2) and upstream splicing factor poly-pyrimidine tract binding protein (PTBP1) have been observed regardless of genetic background, ${ }^{1}$ suggesting that targeting the PTBP1/ PKM2 axis could be a potent therapeutic strategy in PAH. Apigenin has been recognised for its low toxicity and ability to suppress PTBP1 and PKM2-driven Warburg glycolysis and tumorigenesis. ${ }^{2}$ This work investigates apigenin's effects on the PKM2/PTBP1 axis in ECs; whether treatment could correct hallmark characteristics of PAH EC dysfunction; and the influence of BMPR2 mutations.

Methods Here, we examined the proteomic, metabolic and functional profiles of blood outgrowth endothelial cells (BOECs) obtained from healthy control volunteers and PAH patients with BMPR2 mutations, following apigenin treatment or PTBP1/PKM2 knockdown. We hypothesised that, apigenin treatment would reduce glycolysis by inhibiting PTBP1 driven splicing of PKM into PKM2, and PKM2-dependent expression of glycolytic pathway components, such as lactate-dehydrogenase $\mathrm{A}$ (LDHA) and lactate production.

Results In control and BMPR2 mutant BOECs, apigenin inhibited expression of PTBP1 and tetrameric PKM2. In control and BMPR2 mutant BOECs, apigenin also suppressed LDHA protein expression and lactate production. Apigenin inhibited cell cycle progression and caspase $3 / 7$ activity in control and BMPR2 mutant BOECs, suggesting treatment may reduce EC susceptibility to proliferation and apoptosis, hallmarks of $\mathrm{PAH}$ ECs.

Conclusions Apigenin treatment may suppress EC glycolysis, possibly through suppression of PKM2-driven glycolytic gene expression and tetrameric activity. This encouraging data suggests apigenin may correct endothelial cell dysfunction observed in $\mathrm{PAH}$, including susceptibility to apoptosis and proliferation.

\section{REFERENCES}

1. Caruso $P$, et al. Identification of MicroRNA-124 as a Major Regulator of Enhanced Endothelial Cell Glycolysis in Pulmonary Arterial Hypertension via PTBP1 (Polypyrimidine Tract Binding Protein) and Pyruvate Kinase M2. Circulation 2017;136:2451-2467.

2. Shan $\mathrm{S}$, et al. Apigenin restrains colon cancer cell proliferation via targeted blocking of pyruvate kinase M2-dependent glycolysis. I Agric Food Chem 2017;65:8136-8144. 


\section{The clinical management of acute asthma}

\section{S1 OBESE, NON-EOSINOPHILIC ASTHMA: FREQUENT EXACERBATORS IN A REAL-WORLD SETTING}

S Ananth, A Navarra, R Vancheeswaran. West Hertfordshire Hospitals NHS Trust, London, UK

\subsection{6/thorax-2021-BTSabstracts.7}

Introduction In the UK, asthma deaths are at their highest level this century (1). Increased recognition of at-risk patients is needed. This study phenotyped frequent asthma exacerbators, and used machine learning to predict frequent exacerbators. We hypothesised that frequent exacerbators would have more severe peripheral eosinophilia than infrequent exacerbators.

Methods Patients admitted to Watford General Hospital with an asthma exacerbation between $1^{\text {st }}$ March $2018-1^{\text {st }}$ March 2020 were included. Patient data was retrospectively collected from hospital and primary care records. Patients were organised into two groups: "Infrequent Exacerbator" (1 admission in the previous 12 months) and "Frequent Exacerbator" ( $\geq 2$ admissions in the previous 12 months). Good adherence to inhaled corticosteroids (ICS) was defined as medication possession ratio (MPR) $\geq 0.8$; poor adherence was defined as MPR $\leq 0.5$. Machine learning models were used to predict frequent exacerbators.

Results 200 patients admitted for asthma exacerbations were randomly selected $(73 \%$ female; mean age $47.8 \pm 19.3$ years; table 1). Peripheral eosinophilia was uncommon in either group (19\% vs 21\%). More frequent exacerbators were being treated with high-dose ICS $(46.5 \%$ vs $23.2 \%$; P $<0.001)$, and frequent exacerbators used more SABA inhalers (10.9 vs $7.40 ; \mathrm{P}=0.01)$ in the year preceding the current admission. Good adherence to ICS was similarly low between both groups $(40.0 \%$ vs $48.3 \%)$. BMI was raised in both groups (34.2 vs 30.9). Logistic regression classifier was the most accurate machine learning model for predicting frequent exacerbators $(\mathrm{AUC}=0.80)$.

Abstract S1 Table 1 Characteristics of patients admitted for asthma exacerbations

\begin{tabular}{|c|c|c|c|}
\hline & Infrequent Exacerbators & Frequent Exacerbators & P Value \\
\hline n & 100 & 100 & \\
\hline Age, years & $46.5 \pm 20.9$ & $49.0 \pm 17.5$ & 0.25 \\
\hline Female (\%) & 69.0 & 77.0 & 0.20 \\
\hline \multirow[t]{3}{*}{ Ethnicity (\%) } & Caucasian 82.0 & Caucasian 83.0 & 0.85 \\
\hline & Asian 15.0 & Asian 13.0 & 0.68 \\
\hline & Afro-Caribbean 1.0 & Afro-Caribbean 1.0 & 1.00 \\
\hline Exacerbations managed in primary care in the last 12 months & $0.79 \pm 1.15$ & $1.92 \pm 1.83$ & $<0.001^{* * *}$ \\
\hline FEV1/FVC (\%) & $71.0 \pm 13.4$ & $70.9 \pm 16.8$ & 0.96 \\
\hline Obstructive lung function (\%) & 34.5 & 39.1 & 0.60 \\
\hline FeNO, ppb & $42.3 \pm 57.1$ & $24.8 \pm 13.6$ & 0.97 \\
\hline High FeNO (\%) & 27.3 & 12.5 & 0.44 \\
\hline Blood eosinophils, $\times 10^{9} / \mathrm{L}$ & $0.27 \pm 0.39$ & $0.32 \pm 0.41$ & 0.45 \\
\hline Eosinophilia (\%) & 19.0 & 21.0 & 0.72 \\
\hline Blood neutrophils, $\times 10^{9} / \mathrm{L}$ & $7.91 \pm 3.87$ & $7.70 \pm 3.11$ & 0.87 \\
\hline Neutrophilia (\%) & 45.0 & 49.0 & 0.57 \\
\hline Total lgE, kU/L & $470.3 \pm 870.3$ & $378.9 \pm 755.1$ & 0.18 \\
\hline High IgE (\%) & 68.2 & 52.9 & 0.11 \\
\hline Patients with CT scan changes (\%) & 78.0 & 90.2 & 0.09 \\
\hline ICS-LABA (\%) & 60.6 & 88.9 & $<0.001^{* * *}$ \\
\hline High-dose ICS (\%) & 23.2 & 46.5 & $<0.001^{* * *}$ \\
\hline Long-term OCS (\%) & 3.03 & 10.1 & $0.04^{*}$ \\
\hline OCS courses in past year & $0.99 \pm 1.21$ & $2.06 \pm 2.34$ & $0.005^{* *}$ \\
\hline SABA dispensed in past year & $7.40 \pm 7.89$ & $10.94 \pm 9.39$ & $0.01^{*}$ \\
\hline SABA overuse (\%) & 64.8 & 78.6 & 0.58 \\
\hline ICS MPR & $0.72 \pm 0.44$ & $0.72 \pm 0.40$ & 0.66 \\
\hline Good ICS adherence (\%) & 48.3 & 40.0 & 0.35 \\
\hline Poor ICS adherence (\%) & 36.7 & 30.8 & 0.49 \\
\hline \multicolumn{4}{|l|}{ Past Medical History } \\
\hline COPD (\%) & 5.10 & 3.03 & 0.46 \\
\hline GORD (\%) & 30.6 & 46.5 & $0.02^{*}$ \\
\hline Depression (\%) & 29.6 & 32.3 & 0.68 \\
\hline Ex or current smoker (\%) & 64.5 & 69.9 & 0.51 \\
\hline BMI & $30.9 \pm 6.06$ & $34.2 \pm 9.48$ & 0.14 \\
\hline Obese (\%) & 63.4 & 63.6 & 0.98 \\
\hline Follow-up within 4 weeks (\%) & 54.0 & 67.0 & 0.06 \\
\hline
\end{tabular}

Data presented as mean \pm standard deviation, unless stated differently.

FEV1/FVC: ratio of Forced Expiratory Volume in 1 second to the Forced Vital Capacity. FeNO: fractional exhaled nitric oxide. ICS: inhaled corticosteroid. LABA: long-acting $\beta_{2}$-agonist. OCS: oral corticosteroid. SABA: short-acting $\beta_{2}$-agonist. MPR: medication possession ratio. COPD: chronic obstructive pulmonary disease. GORD: gastro-oesophageal reflux disease.

High FeNO defined as FeNO $>40$. Eosinophilia defined as blood eosinophils $\geq 0.5 \times 10^{9} / \mathrm{L}$. Neutrophilia defined as blood neutrophils $\geq 7.2 \times 10^{9} / \mathrm{L}$. High IgE defined as serum IgE $\geq 81 \mathrm{kU} / \mathrm{L}$. Good ICS adherence defined as ICS MPR $\geq 0.8$. Poor ICS adherence defined as ICS MPR $\leq 0.5$. SABA overuse defined as $\geq 3$ SABA inhalers per year. 